\title{
Essential Gene(s) Targeted by Peptide Nucleic Acids Kills Mycobacterium smegmatis in Culture and in Infected Macrophages
}

\author{
Md. Ariful Islam ${ }^{1,2}$, Mst. Minara Khatun ${ }^{1,2}$, Nammalwar Sriranganathan ${ }^{1}$, Stephen M. Boyle ${ }^{1 *}$ \\ ${ }^{1}$ Center for One Health Research, Virginia-Maryland College of Veterinary Medicine, Virginia Tech, Blacksburg, VA, USA \\ ${ }^{2}$ Department of Microbiology \& Hygiene, Bangladesh Agricultural University, Mymensingh, Bangladesh \\ Email: *smboyle@vt.edu
}

How to cite this paper: Islam, M.A., Khatun, M.M., Sriranganathan, N. and Boyle, S.M. (2021) Essential Gene(s) Targeted by Peptide Nucleic Acids Kills Mycobacterium smegmatis in Culture and in Infected Macrophages. Advances in Infectious Diseases, 11, 156-164.

https://doi.org/10.4236/aid.2021.112015

Received: March 13, 2021

Accepted: April 16, 2021

Published: April 19, 2021

Copyright $\odot 2021$ by author(s) and Scientific Research Publishing Inc. This work is licensed under the Creative Commons Attribution International License (CC BY 4.0).

http://creativecommons.org/licenses/by/4.0/

(c) (i) Open Access

\begin{abstract}
Background: Antisense peptide nucleic acids (PNAs) exhibit growth inhibitory effects on bacteria by inhibiting the expression of essential genes and could be promising therapeutic agents for treating bacterial infections. A study was carried out to determine the efficacy of several antisense PNAs in inhibiting extracellular and intracellular growth of Mycobacterium smegmatis. Methods. Six PNAs obtained from a commercial supplier were tested to evaluate the inhibitory effect on bacterial growth by inhibiting the expression of the following essential genes: inhA (a fatty acid elongase), $r p s L$ (ribosomal S12 protein), gyrA (DNA gyrase), pncA (pyrazinamidase), polA (DNA polymerase I) and rpoC (RNA polymerase $\beta$ subunit) of $M$. smegmatis. Each PNA was tested at $20 \mu \mathrm{M}, 10 \mu \mathrm{M}, 5 \mu \mathrm{M}$ and $2.5 \mu \mathrm{M}$ concentrations to determine whether they caused a dose dependent killing of $M$. smegmatis cultured in Middlebrook 7H9 broth or in a J774A.1 murine macrophage cell line. Results: In Middlebrook broth, the strong growth inhibitory effect against $M$. smegmatis was observed by PNAs targeting the inhA and rpsL genes at all four concentrations. The PNAs targeting the pncA, polA and rpoC genes were found to exhibit strong growth inhibition against $M$. smegmatis but only at $20 \mu \mathrm{M}$ concentration. No growth inhibition of $M$. smegmatis was seen in pure culture when treated with PNAs targeting gyrA and a mismatch PNA targeting dnaG (DNA primase). All six PNAs showed killing of M. smegmatis in J774A.1 macrophage cell line that were statistically significant $(\mathrm{p}<0.05)$. Conclusion: It may be concluded from this study that PNAs could be potential therapeutics for mycobacterial infections.
\end{abstract}

\section{Keywords}

Middlebrook 7H9 Broth Culture, J774A.1 Murine Macrophage Cell Line, 
Antisense Therapy, Peptide Nucleic Acid, Cell Penetrating Peptide, Mycobacterium

\section{Introduction}

Mycobacterium smegmatis is an avirulent bacterial genus present in the soil and smegma that shows many features similar to Mycobacterium tuberculosis (Mtb), responsible for causing tuberculosis in humans [1]. Tuberculosis is one of the major causes of human death in the world. Around one-third of the human population is estimated to be infected with $M t b$. Antibiotics commonly used to treat the $M t b$ in humans require prolonged therapy and they have many toxic side effects. The antibiotics used against $M t b$ cannot readily penetrate through the lipid-rich mycobacterial cell wall that represents a hurdle in the treatment of clinical disease [2] [3]. Moreover, emergence of multidrug-resistant (MDR) strains of $M t b$ is a great challenge to treat tuberculosis with a combination of antibiotics. It is very essential to develop an effective treatment for MDR Mtb without toxicity and that enables highly targeted delivery of antimicrobials to their intracellular niche.

Antisense/antigene therapy using peptide nucleic acids (PNAs) has the potential to help control MDR bacterial infections. PNA is DNA mimic with a peptide backbone instead of sugar (deoxyribose) [4]. It binds to form double stranded like DNA and complexes with complementary DNA or RNA. Short antisense oligonucleotides (10 - 12 mers) PNAs can bind at start codon and upstream regions of essential genes. Addition of cell penetrating peptide (CPP) to the PNA transports it across cell membranes and bacterial cell envelopes, which is essential for its antimicrobial effects [5].

Recently PNA therapy has shown promising results in inhibiting the growth of Salmonella typhimurium, Staphylococcus aureus and Escherichia coli, by down regulating the functions of the essential genes of these bacteria [6] [7] [8]. A previous study showed antisense PNA targeting only inhA gene inhibited the growth of M. smegmatis in pure culture [9]. As Mycobacterium spp. are intracellular pathogens, the growth inhibitory effects of antisense PNA must be studied inside the macrophage. To the best of our knowledge, no study has been performed so far to evaluate the growth inhibitory functions of anti-sense PNAs against Mycobacterium targeting one of its essential genes inside the macrophage. In this study, we have designed 6 antisense PNAs complementary to the translation start codon region on the mRNA of six essential genes of $M$. smegmatis; these are inhA, rpsL, gyrA, pncA, polA and rpoC. PNAs were conjugated with cell penetrating peptide ( $\mathrm{CPP}=\mathrm{KFFKFFKFFK}$ ) to aid cell membrane passage [10]. The objectives of this study were to evaluate the inhibitory function of six anti-sense PNAs against $M$. smegmatis in pure culture and inside the macrophages and to identify the most suitable gene targets of Mycobacterium for antisense therapy. 


\section{Materials and Methods}

\subsection{Bacterial Strain}

M. smegmatis was obtained from the laboratory repository of the Center for Molecular Medicine and Infectious Disease (CMMID) now called Center for One Health Research (COHR), Virginia-Maryland College of Veterinary Medicine at Virginia Tech.

\subsection{Bacterial Growth in Pure Culture}

A frozen stock of $M$. smegmatis was diluted in Middlebrook 7H9 broth (Sigma) enriched with $10 \% \mathrm{ADC}$ incubated at $37^{\circ} \mathrm{C}$ aerobically for $48 \mathrm{~h}$ on a shaker incubator until the $\mathrm{OD}_{600} 0.5$ was reached.

\subsection{Peptide Nucleic Acids}

The list of PNAs shown in Table 1 was synthesized by Panagene Inc. (Daejeon, Republic of Korea). PNAs conjugated with cell penetrating peptide $(\mathrm{KFF})_{3} \mathrm{~K}$, where $\mathrm{K}$ is lysine and $\mathrm{F}$ is phenylalanine, to facilitate PNAs uptake through bacterial cell envelope.

\subsection{Growth of M. smegmatis in Pure Culture}

An overnight culture of M. smegmatis was diluted in 7H9 broth to obtain $6 \times 10^{4}$ colony forming units (CFUs)/ml and incubated with either $20 \mu \mathrm{M}, 10 \mu \mathrm{M}, 5 \mu \mathrm{M}$ or $2.5 \mu \mathrm{M}$ concentration PNAs (volume $=100 \mu \mathrm{l}$ ) in triplicate using a 96 well, low adhesion microtiter plate (Corning Inc. Cat. \# 3474). The plate was sealed with an adhesive lid (Microseal B, Bio-Rad) and incubated at $37^{\circ} \mathrm{C}$ for $48 \mathrm{~h}$ on a SPECTRA max 340PC with shaker incubator; growth was monitored by measuring optical density of the culture spectrophotometrically $(600 \mathrm{~nm})$. All PNA

Table 1. M. smegmatis targeted genes and PNA-specific sequence.

\begin{tabular}{|c|c|c|c|}
\hline Gene target & Gene accession no. & CPP-PNA sequence sequence ${ }^{a}$ & Proposed functions/Drug \\
\hline $\operatorname{inh} A$ & MSMEG_3151 & H-KFFKFFKFFK-O-gtcatttggt- $\mathrm{NH}_{2}$ & $\begin{array}{l}\text { Isoniazid Enoyl-ACP reductase (acyl carrier protein) of fatty } \\
\text { acid synthase II needed to elongate long chain fatty } \\
\text { acids for the synthesis of mycolic acid/Isoniazid (INH) }\end{array}$ \\
\hline$r p s L$ & MSMEG_1398 & H-KFFKFFKFFK-O-ttggcatgta- $\mathrm{NH}_{2}$ & Ribosomal protein S12/Streptomycin \\
\hline gyrA & MSMEG_0456 & H-KFFKFFKFFK-O-catatcgtcgga- $\mathrm{NH}_{2}$ & DNA gyrase subunit A/Fluoroquinolones \\
\hline pncA & MSMEG_6506 & H-KFFKFFKFFK-O-catgcctcga- $\mathrm{NH}_{2}$ & $\begin{array}{c}\text { PZA inhibits the activity of FAS I (palmitic acid) in } \\
\text { PZA-susceptible } M \text {. smegmatis strains/Pyrazinamide (PZA) }\end{array}$ \\
\hline polA & MSMEG_3839 & H-KFFKFFKFFK-O-ttcatgcctgt- $\mathrm{NH}_{2}$ & DNA polymerase I \\
\hline rpoC & MSMEG_1368 & $\mathrm{H}$-KFFKFFKFFK-O-catcgtaactc- $\mathrm{NH}_{2}$ & RNA polymerase subunit $\beta$ \\
\hline $\begin{array}{l}\text { dnaG (negative } \\
\text { control PNA) }\end{array}$ & BR_1480 & H-KFFKFFKFFK-O-cattacagatt- $\mathrm{NH}_{2}$ & Mismatch PNA for DNA primase \\
\hline
\end{tabular}

aThe PNAs and CPP were synthesized (Panagene Inc., Daejeon, South Korea) and joined by an ethylene glycol linker designated as "O"; a glycol linker of nine atoms used to distance the hybridization portion of the molecule from the CPP. The bolded "cat" indicates the PNA sequence complementary to ATG start codon contained in the specified gene. 
treated cultures of $M$. smegmatis were removed after $48 \mathrm{~h}$ and were serially diluted and plated on $7 \mathrm{H} 10$ Middlebrook agar. The plates were incubated at $37^{\circ} \mathrm{C}$ for 2 to 4 days to determine the number of viable cells ( $\mathrm{CFU} / \mathrm{ml})$.

\subsection{Growth of M. smegmatis inside J774A.1 Murine Macrophage}

Intracellular activity of PNAs was evaluated in J774A.1 murine macrophage cell line (ATCC, Manassas, VA). J774A.1 cells were grown in Dulbecco's Modified Eagle Medium (DMEM) (Sigma) supplemented with heat inactivated 10\% fetal bovine serum. The cells were grown at $37^{\circ} \mathrm{C}$ in an atmosphere containing $5 \%$ $\mathrm{CO}_{2}$. J774A.1 cells were plated in $200 \mu \mathrm{l}$ of DMEM at a concentration of $6.5 \times 10^{4}$ cells per well in 96-well tissue culture white plates with clear bottoms (Corning Inc. Cat. \#3596) and allowed to adhere overnight. For the infection, mid-log phase M. smegmatis $\left(\mathrm{OD}_{600}=0.5\right)$ were washed twice with $\mathrm{PBS}$, centrifuged at $2800 \times \mathrm{G}$ for $15 \mathrm{~min}$ and then resuspended in DMEM and sonicated for $2 \times 30$ seconds in a bath sonicator to disperse clumps. The bacteria in the supernatant were then diluted in DMEM to a concentration of $1.6 \times 10^{6}$ CFUs; $100 \mu \mathrm{l}$ of bacterial suspension was added to each well of the J774A.1 cells. After $1 \mathrm{~h}$ of infection at $37^{\circ} \mathrm{C}$ in $5 \% \mathrm{CO}_{2}$, J774A.1 cells were washed twice with gentamicin (10 $\mu \mathrm{g} / \mathrm{ml})$ to eliminate any extracellular bacteria. Cells were treated with PNAs designed to target inhA, rpsL, pncA, rpoC, polA, gyrA and $d n a G$. The concentrations of each PNA were $0.2 \mu \mathrm{M}, 2 \mu \mathrm{M}$ and $20 \mu \mathrm{M}$; rifampin concentration was 16 $\mu \mathrm{g} / \mathrm{ml} .100 \mu \mathrm{l}$ of each PNA concentration or rifampin was added to infected J774A. 1 cells in triplicate and incubated at $37^{\circ} \mathrm{C}$ under $5 \% \mathrm{CO}_{2}$ for $24 \mathrm{~h}$. The infected macrophages were lysed with $100 \mu \mathrm{l}$ of $0.1 \%$ TritonX-100 (Sigma) and serially diluted in PBS-Tween and $25 \mu$ lysed cells were inoculated onto Middlebrook7H10 agar (Difco) plates for viable count determination. The CFU was determined just after the infection (day 0 , i.e., post gentamicin treatment) and at the end of the experiment.

\subsection{Macrophage Viability and Toxicity Assay}

Cell viability assay using tetrazolium compound [CellTiter $96{ }^{\circledR}$ Aqueous Non-Radioactive Cell Proliferation Assay (MTS); Promega, Fitchburg, WI] was conducted to measure the growth inhibitory effects of PNAs linked with CPP on J774A.1 cells. The macrophages were treated with $20 \mu \mathrm{M}$ PNA linked with CPP and incubated at $37^{\circ} \mathrm{C}$ under $5 \% \mathrm{CO}_{2}$ for $24 \mathrm{~h}$. The viable cell numbers were determined at $490 \mathrm{~nm}$ absorbance due to the formazone product. The trypan blue exclusion assay was used to measure cell viability after $24 \mathrm{~h}$ of PNA treatment. The number of viable macrophage cells was assessed using a hemocytometer. The percentage of living cells was determined by counting at least 100 cells.

\subsection{Statistical Analysis}

CFU data of PNAs treated and untreated infected cells were analyzed for statistical significance using student's $t$ test (Microsoft Excel version 2010, USA). A P 
value of $\leq 0.05$ was considered to be statistically significant.

\section{Results}

\subsection{Inhibition of Growth in Pure Culture}

The results of growth inhibitory assays of six PNA showed that only two PNAs (inh $A$ and $r p s L$ ) out of six essential genes were found to exhibit strong growth inhibition at all concentrations. Three PNAs ( $p n c A$, polA and rpoC) showed growth inhibitory effect only at the highest concentration used i.e., $20 \mu \mathrm{M}$ concentration. One PNA ( $g y r A$ ) and a mismatch PNA did not show any growth inhibitory effect. The growth inhibition effects of PNAs are summarized in Table 2.

\subsection{Inhibition of Growth inside Murine Macrophage}

Growth inhibitory effects of PNAs were measured at $24 \mathrm{~h}$ post-treatment. The results show that all six PNAs significantly decreased the intracellular growth of M. smegmatis ( $p>0.05)$. PNAs targeting inhA and $r p s L$ showed concentration dependent growth inhibition as compared to remaining four PNAs. Complete growth inhibition of intracellular growth was observed for $r p s L$ PNA at $20 \mu \mathrm{m}$ concentration. The ability of PNAs to inhibit growth of M. smegmatis inside murine macrophages is shown in Figure 1.

\subsection{Macrophage Viability and Toxicity Assay}

The viability and reproductive capacity of J774A.1 macrophage cell line was tested by treating the cell line with PNAs linked or unlinked to CPP or by CPP only at $24 \mathrm{~h}$ post treatment. No visible toxic effects were seen both in trypan blue exclusion assay and MTT assay (data not shown). None of the tested concentrations of PNAs affected either morphology or doubling time of J774.A1 cells (data not shown).

Table 2. The ability of PNAs to inhibit M. smegmatis in pure culture.

\begin{tabular}{|c|c|c|c|c|}
\hline \multirow{2}{*}{ Gene target } & \multicolumn{4}{|c|}{ PNA concentration } \\
\hline & $20 \mu \mathrm{M}$ & $10 \mu \mathrm{M}$ & $5 \mu \mathrm{M}$ & $2.5 \mu \mathrm{M}$ \\
\hline $\operatorname{dna} G^{*}$ & - & - & - & - \\
\hline $\operatorname{inh} A$ & ++++ & ++++ & ++++ & ++++ \\
\hline$r p s L$ & ++++ & ++++ & ++++ & ++++ \\
\hline gyrA & - & - & - & - \\
\hline pncA & ++++ & - & - & - \\
\hline polA & ++++ & - & - & - \\
\hline rpoC & ++++ & - & - & - \\
\hline
\end{tabular}

Abbreviations: ++++ , Strong inhibition of growth; -, No growth inhibition, ${ }^{\star}$, mismatch control PNA. 


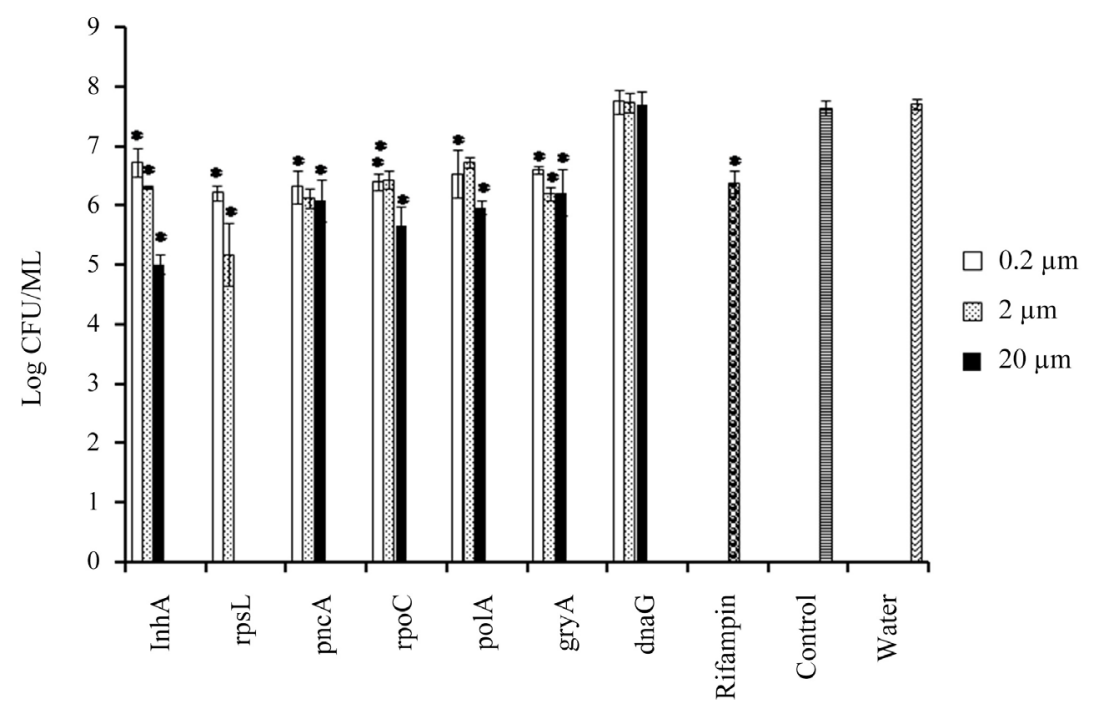

Figure 1. Bacteriocidal activity of PNA targeting inhA, rpsL, pncA, rpoC, polA and gyrA against M. smegmatis inside J774A.1 murine macrophage cells. Macrophages in $100 \mu \mathrm{l}$ of DMEM were infected with $M$. smegmatis at a MOI of 100 (seeding density and infection dose per well were $7.0 \times 10^{4}$ and $7.0 \times 10^{6}$ respectively. After $1 \mathrm{~h}$ post infection, extracellular bacteria were washed twice with $100 \mu \mathrm{l}$ of PBS + gentamicin $(10 \mu \mathrm{g} / \mathrm{ml})$. Infected cells were resuspended in $100 \mu \mathrm{l}$ of DMEM treated with inhA, rpsL, pncA, rpoC, polA and $\operatorname{gyr} A$ (at $0.2,2$ and $20 \mu \mathrm{m}$ ). Three wells were untreated controls and three wells were treated with water and three wells with rifampin $(16 \mu \mathrm{g} / \mathrm{ml})$. Cells were lysed at $24 \mathrm{hr}$ post infection, serially diluted and plated onto Middlebrook $7 \mathrm{H} 9$ agar and incubated at $37^{\circ} \mathrm{C}$ for $48 \mathrm{hr}$ for measuring CFU. Results were expressed as mean Log CFU of three wells \pm SD. Complete killing of bacteria was observed in wells treated with $r p s L$ at $20 \mu \mathrm{M}$ concentration. CFU data of treated and untreated cells were analyzed for statistical significance by student's $t$ test. Statistically significant difference between treated and untreated cells were indicated by asterisk $\left({ }^{*} p<0.05\right)$.

\section{Discussion}

The identification of essential genes of microbes through microbial genomics helps selecting potential targets for antisense inhibition. Antisense therapy using PNAs has become an attractive tool for controlling bacterial growth. PNAs can produce strong complexes with complementary strands of DNA or RNA and inhibit expression of microbial genes required for their growth in dose dependent manner at low micromolar concentration [11] [12]. Bacteria living within eukaryotic host tissue constitute a significant challenge for antisense treatment [13]. The PNAs linked with cell penetrating peptides are found effective in inhibiting growth of microbes both in vitro and in vivo [8]. The high prevalence of extreme drug resistant $M t b$ leaves no treatment option for patients that leads to increased morbidity and mortality rate worldwide. In this situation there is an urgent need to develop new drugs against $M t b$ that could be alternatives to traditional antibiotics. The present study evaluated six PNAs against $M$. smegmatis both in vitro and in vivo. In this study six PNAs were selected using the bioinformatics resources and tools. The PNAs were linked with cell penetrating peptide (CPP): CPP-O-PNA. These were significantly more effective in inhibiting expression of 
their targets as compared to non-CPP linked PNAs [8]. Cationic CPPs are known to bind with proteoglycans of eukaryotic cells and then enter into the cells by endocytosis [14] [15]. To develop a new antimicrobial, selection of essential genes as targets in bacteria for antisense PNAs is important [16]. The present study selected six essential genes (inhA, rpsL, gyrA, pncA, polA and $r p o C$ ) of $M$. smegmatis for development of effective antisense treatment targets. PNAs in this study were found to be effective in inhibiting the growth of $M$. smegmatis both in pure culture and murine macrophages. The antibacterial effect of PNA depends on bioavailability of PNA inside the bacterial cell while the lipid enriched cell wall is the major barrier of entrance to PNA inside Mycobacterium [2] [6]. Although gyrA PNA did not show growth inhibition of $M$. smegmatis in pure culture, it was found to have growth inhibitory effect against M. smegmatis inside murine macrophage. Growth inhibitory effects of gyrA PNA against Klebsiella pneumonia were observed both in pure culture and inside human epithelial cells at $20 \mu \mathrm{M}$ concentration [17]. PNAs targeting rpsL and inh $A$ were found to be most effective in killing M. smegmatis as compared to other essential gene targets. A dose dependent growth inhibition of $M$. smegmatis was observed for both rpsL and inhA PNAs. The susceptibility of $M$. smegmatis by inhA PNA to growth inhibition was originally shown by Kulyte et al., [9] and occurred at concentrations between 2 and $15 \mathrm{uM}$.

There was no detectable toxic effect on macrophages noticed either in a trypan blue exclusion assay or in the cell viability MTS assay even at the highest concentration $(20 \mu \mathrm{M})$ of PNA used suggesting that the PNA is specific for $M$. smegmatis.

Antisense oligonucleotides are designed to bind the target mRNA to prevent translation or bind DNA to prevent gene transcription respectively. They can bind to the specific sequence of RNA and DNA by Watson-Crick base pairing which leads to a variety of post-binding events [17] [18]. Data from this study indirectly indicates that PNAs exerted antimicrobial activity by inhibiting the expression of essential gene(s) involved in different types of macromolecular synthesis.

Sequence homology is necessary for PNA binding in order to selectively hybridize to complementary nucleic acids of either chromosomal or messenger RNA of $M$. smegmatis. ${ }^{6}$ This study demonstrated sequence specific binding of PNAs with the gene targets since mismatch a PNA lacking sequence homology did not show growth inhibition against $M$. smegmatis both in pure culture and in M. smegmatis infected J774A.1 cells. The antimicrobial effect observed against M. smegmatis by antisense peptide PNAs in murine macrophage cell line shows the potential for the development of PNA based antibiotic against mycobacterial infection in humans.

\section{Conclusion}

M. smegmatis is susceptible in pure culture to PNA mediated growth inhibition by targeting genes involved in cell envelope synthesis, DNA and mRNA synthe- 
sis, and protein synthesis. M. smegmatis growing in a macrophage cell line is also susceptible to PNA targeting genes involved in cell envelope and nucleic acid synthesis of the bacterium. Data from this study suggest that PNAs targeting inh $A$ and rpsL could be useful as antisense therapy for Mycobacterium infections. Further studies to examine the effect of PNAs administered as nanoparticles targeted to macrophages in mice infected with $M$. smegmatis will need to be carried out.

\section{Acknowledgements}

We thank Rebecca Wattam (Virginia Bioinformatics Institute) for help with PNA design.

\section{Funding}

This research was funded through grants from NIH to SMB (5R03AI083735-02) and from The Islamic Development Bank to MAI.

\section{Ethical Approval}

Not required.

\section{Disclosure}

A poster with interim findings was presented at the Euro-Scicon conference 2013 held on 21 March 2013 at the Royal College of Pathologist, London, UK. The poster's abstract was published in https://www.euroscicon.com/documents/21March2013TB.pdf.

\section{Conflicts of Interest}

The authors declare no conflicts of interest regarding the publication of this paper.

\section{References}

[1] Wang, R., Prince, J.T. and Marcotte, E.M. (2005) Mass Spectrometry of the $M$. smegmatis Proteome: Protein Expression Levels Correlate with Function, Operons, and Codon Bias. Genome Research, 15, 1118-1126. https://doi.org/10.1101/gr.3994105

[2] Draper, P. (1998) The Outer Parts of the Mycobacterial Envelope as Permeability Barriers. Frontier Bioscience, 3, D1253-D1261.

[3] Brennan, P.J. and Nikaido, H. (1995) The Envelope of Mycobacteria. Annual Review of Biochemistry, 64, 29-63. https://doi.org/10.1146/annurev.bi.64.070195.000333

[4] Nielsen, P.E., Egholm, M., Berg, R.H. and Buchardt, O. (1991) Sequence-Selective Recognition of DNA by Strand Displacement with a Thymine-Substituted Polyamide. Science, 254, 1497-1500. https://doi.org/10.1126/science.1962210

[5] Patel, R.R., Sundin, G.W., Yang, C.H., Wang, J., Huntley, R.B., Yuan, X. and Zeng, Q. (2017) Exploration of Using Antisense Peptide Nucleic Acid (PNA)-Cell Penetrating Peptide (CPP) as a Novel Bactericide against Fire Blight Pathogen Erwinia 
amylovora. Frontier in Microbiology, 8, Article No. 687. https://doi.org/10.3389/fmicb.2017.00687

[6] Sofi, M.A. and Seleem, M.N. (2012) Targeting Essential Genes in Salmonella enterica Serovar Typhimurium with Antisense Peptide Nucleic Acid. Antimicrobial Agents and Chemotherapy, 56, 6407-6409. https://doi.org/10.1128/AAC.01437-12

[7] Nekhotiaeva, N., Awasthi, S.K., Nielsen, P.E. and Good, L. (2004) Inhibition of Staphylococcus aureus Gene Expression and Growth Using Antisense Peptide Nucleic Acid. Molecular Therapy, 10, 652-659. https://doi.org/10.1016/j.ymthe.2004.07.006

[8] Good, L., Awasthi, S.K., Dryselius, R., Larsson, O. and Neilsen, P.E. (2001) Bacterial Antisense Effects of Peptide-PNA Conjugates. Natural Biotechnology, 19, 360-364. https://doi.org/10.1038/86753

[9] Kulyte, A., Nefhotiaeva, N., Awasthi, S.K. and Good, L. (2005) Inhibition of Mycobacterium smegmatis Gene Expression and Growth Using Antisense Peptide Nucleic Acid. Journal of Molecular Microbiology and Biotechnology, 9, 101-109. https://doi.org/10.1159/000088840

[10] Dryselius, R., Aswasti, S.K., Rajarao, G.K., Nielsen, P.E. and Good, L. (2003) The Translation Start Codon Region Is Sensitive to Antisense PNA Inhibition in Escherichia coli. Oligonucleotides, 13, 427-433. https://doi.org/10.1089/154545703322860753

[11] Hatamoto, M., Ohashi, A. and Imachi, H. (2010) Peptide Nucleic Acids (PNAs) Antisense Effect to Bacterial Growth and Their Application Potentiality in Biotechnology. Applied Microbiology and Biotechnology, 86, 397-402. https://doi.org/10.1007/s00253-009-2387-8

[12] Bai, H., Xue, X., Hou, Z., Zhou, Y., Meng, J. and Luo, X. (2010) Antisense Antibiotics: A Brief Review of Novel Target Discovery and Delivery. Current Drug Discovery Technologies, 7, 76-85. https://doi.org/10.2174/157016310793180594

[13] Mitev, G.M., Mellbye, B.L., Iversen, P.L. and Geller, B.L. (2009) Inhibition of Intracellular Growth of Salmonella enterica Serovar Typhimurium in Tissue Culture by Antisense Peptide-Phosphorodiamidate Morpholino Oligomer. Antimicrobial Agents and Chemotherapy, 53, 3700-3704. https://doi.org/10.1128/AAC.00099-09

[14] Abes, R., Aruzumanov, A.A., Moulton, H.M., Ivanova, G.D., Iversen, P.L., Gait, M.J., et al. (2007) Cell-Penetrating-Peptide-Based Delivery of Oligonucleotides: An Overview. Biochemical Society Transactions, 35, 775-779.

https://doi.org/10.1042/BST0350775

[15] Jones, S.W., Christian, R., Bundell, K., Voyce, C., Brockbank, S.M.V., Newhan, P. and Lindsay, M.A. (2005) Characterisation of Cell-Penetrating Peptide-Mediated Peptide Delivery. British Journal of Pharmacology, 145, 1093-1102. https://doi.org/10.1038/sj.bjp.0706279

[16] Howl, J., Nicholl, I.D. and Jones, S. (2007) The Many Futures for Cell-Penetrating Peptides: How Soon Is Now? Biochemical Society Transactions, 35, 767-769. https://doi.org/10.1042/BST0350767

[17] Kurupati, P., Tan, K.S.W., Kumarasinghe, G. and Poh, C.L. (2007) Inhibition of Gene Expression and Growth by Antisense Peptide Nucleic Acids in a Multi-Resistant-Lactamase-Producing Klebsiella pneumoniae Strain. Antimicrobial Agents and Chemotherapy, 51, 805-811. https://doi.org/10.1128/AAC.00709-06

[18] Zamecnik, P. (1997) Background of the Antisense Oligonucleotide Approach to Chemotherapy. Antisense and Nucleic Acid Drug Development, 7, 199-202.

https://doi.org/10.1089/oli.1.1997.7.199 